\title{
Interglobular Diffusion of an Energy Donor in Triplet-Triplet Energy Transfer in Proteins
}

\author{
Andrey G. Melnikov, ${ }^{1}$ Alexander B. Pravdin, ${ }^{2}$ Vyacheslav I. Kochubey, \\ Anna V. Kuptsova, ${ }^{1}$ and Gennady V. Melnikov ${ }^{1}$ \\ ${ }^{1}$ Saratov State Technical University, Polytehnicheskaya Street 77, Saratov 410054, Russia \\ ${ }^{2}$ Saratov State University, Astrahanskaya Street 83, Saratov 410012, Russia \\ Correspondence should be addressed to Vyacheslav I. Kochubey; saratov_gu@mail.ru
}

Received 10 July 2013; Revised 12 September 2013; Accepted 17 September 2013

Academic Editor: Ekaterina Borisova

Copyright (C) 2013 Andrey G. Melnikov et al. This is an open access article distributed under the Creative Commons Attribution License, which permits unrestricted use, distribution, and reproduction in any medium, provided the original work is properly cited.

\begin{abstract}
The triplet-triplet energy transfer between polar molecules of luminescent probe (eosin) as an energy donor and nonpolar molecules of energy acceptor (anthracene) is studied. Both the donor and the acceptor are bound to human serum albumin by noncovalent bonds. A dependence of rate constant of triplet-triplet energy transfer on human serum albumin concentration is revealed. A rate constant of eosin output from protein globules is determined. It is shown that the energy transfer occurs as a result of interglobular diffusion of eosin. The obtained results indicate that a protein-luminescent probe based sensor can be used for testing a concentration of polycyclic aromatic hydrocarbons in proteins.
\end{abstract}

\section{Introduction}

The fundamental process of electron energy transfer forms a basis of light energy conversion in both natural photoaccepting systems and artificial sensors [1-3]. There is a number of studies of energy transfer within the dispersed phase of microheterogeneous systems; this dispersed phase is the supramolecular structures such as surfactant micelles [4-6] and biopolymer molecules in solution [7-9].

The energy transfer in microheterogeneous media, for example, in a water-micellar media, has some features compared to homogeneous media. The difference is that the donor and acceptor molecules are not uniformly distributed throughout a volume of a solution. They can be located, for example, in a micellar microphase of surfactants solutions, or in a protein globule [10] for liquid protein media where the energy transfer occurs.

One type of energy transfer is a triplet-triplet (T-T) one. This process takes place at a distance between donor and acceptor being less or equal to 3-10 ̊́ [11]. This feature allows one to use the T-T energy transfer between donors and acceptors bound to a human serum albumin (HSA) to determine minor structural variations in proteins [12]. The phosphorescence of a probe, that is, an eosin bound to HSA macromolecules, turned to be sensitive to $\mathrm{pH}$ variations in protein solutions [13] and to the presence of heavy metal ions in proteins. Quenching of the eosin phosphorescence in the presence of heavy metal ions is used thus helping us determine the presence of heavy metals in human serum albumin [14].

Altogether, the use of the triplet states of luminescent probes is a very promising approach for diagnosis of living conditions of biological objects.

In this paper, we consider a triplet-triplet energy transfer between eosin, being an energy donor, and anthracene as an acceptor, both bound to proteins. The T-T energy transfer between eosin and anthracene is studied in detail in $[15,16]$ for homogeneous solutions. These results can be extended to the case of eosin-anthracene interactions in microheterogeneous media such as protein solution. Anthracene is known to be a sort of polycyclic aromatic hydrocarbons (PAHs). Most of PAHs exhibit carcinogenic and mutagenic properties [17-20], and it is very important to develop methods of their detection in biological objects. In particular, elucidating the details of interaction of PAHs with transport proteins, 
including HSA, is of great interest for medicine because the monitoring of $\mathrm{PAH}$ in blood plasma can estimate the risk of cancer development.

Since PAHs effectively interact with blood plasma transport proteins [21], we offer the method of detecting $\mathrm{PAH}$ in plasma using a sensor composed of a protein (HSA) and a luminescent probe (eosin). The aim of the present work is to prove the feasibility of the method under the conditions of low $\mathrm{PAH}$ and probe concentrations.

\section{Materials and Methods}

Studied solutions of eosin (Eosin Y, Sigma), in concentration of $4 \cdot 10^{-6} \mathrm{M}$ were prepared in phosphate buffer $\mathrm{pH}$ 7.4. For the preparation of solutions, twice-distilled water was used. In the experiment, HSA produced by "Sigma, USA" with content of $99 \%$ of base substance was used. In this work, we used $10 \%$ solution of HSA in phosphate buffer $\mathrm{pH} 7.4$, containing $0.15 \mathrm{M} \mathrm{Na}_{2} \mathrm{HPO}_{4}-\mathrm{KH}_{2} \mathrm{PO}_{4}$. Monitoring of eosin dissolving was carried out by measurements of the optical density of the studied solutions. Absorption spectra were recorded on a Lambda 950 spectrophotometer (Perkin Elmer, USA). Fluorescence and phosphorescence spectra were obtained using a spectrofluorometer Perkin Elmer LS45.

Observation of eosin phosphorescence was performed in deoxygenated solutions. Removal of oxygen from the tested solutions was carried out chemically by a well-known method [22] of using sodium sulfite (manufactured by "Reahim," Russia, analytically pure grade) whose concentration in the solution was $0.01 \mathrm{M}$. The anthracene (Fluka) was used as an energy acceptor.

The rate constant of deactivation of triplet states of eosin was determined as follows. At low concentrations of eosin, when concentration quenching of the luminescence can be neglected, the rate of deactivation of electronic excitation energy of the triplet states $\left[{ }^{3} D\right]$ of eosin after pulse photoexcitation is given by [23]

$$
\frac{d\left[{ }^{3} D\right]}{d t}=-k\left[{ }^{3} D\right]-\gamma\left[{ }^{3} D\right]^{2},
$$

where $k$ is the total rate constant of monomolecular and pseudomonomolecular (quenching by impurities) processes of deactivation of triplet molecules energy, and $\gamma$ is the bimolecular rate constant of the deactivation of triplet molecules (triplet-triplet annihilation of eosin molecules).

If the triplet molecules become deactivated primarily as a result of a first-order reaction, that is, $k \gg \gamma\left[{ }^{3} D\right]$, the equation describing the process of deactivation of triplet energy of the molecules is simplified:

$$
\frac{d\left[{ }^{3} D\right]}{d t}=-k\left[{ }^{3} D\right] .
$$

Solving (2) with respect to $\left[{ }^{3} D\right]$, we get

$$
\left[{ }^{3} D(t)\right]=\left[{ }^{3} D\right]_{0} e^{-k t}
$$

The intensity of the eosin phosphorescence $I_{\mathrm{ph}}$ is proportional to the concentration of its triplet molecules $\left[{ }^{3} D\right]$,

$$
I_{\mathrm{ph}}=A\left[{ }^{3} D(t)\right] k_{\mathrm{rad}}
$$

hence,

$$
I_{\mathrm{ph}}=I_{0} e^{-k t}
$$

where $I_{\mathrm{ph}}$ is the phosphorescence intensity at time $t, A$ is hardware function of spectrofluorimeter, $k_{\text {irr }}$ is the rate constant of probe phosphorescence, $\left[{ }^{3} \mathrm{D}\right]_{0}$ and $I_{0}$ are the concentration of triplet molecules and the phosphorescence initial intensity, respectively, $k$ is the rate constant of deactivation of the probe triplet states, and $t$ is time.

Thus, the approximation of experimental data in the coordinates $\ln \left(I_{\mathrm{ph}}^{0} / I_{\mathrm{ph}}\right)$ versus $t$ allows to determine the total monomolecular rate constant of deactivation of triplet molecules $(k)$ and to find a lifetime of the probe triplet states as $\tau=1 / k$.

Statistical processing of the experimental data was performed by the method of least squares. When measuring the phosphorescence intensity resulting from the excitation pulse, the relative error for seven measurements and for validity of 0.95 was $3 \%$. The error in the determination of the rate constants of the phosphorescence decay was $10 \%$.

\section{Results and Discussion}

To study the interaction of proteins with PAHs, we obtained absorption and fluorescence spectra of anthracene-HSA solutions, with HSA concentration of $C_{\mathrm{HSA}}=1 \mathrm{mg} / \mathrm{mL}$ and $C_{\mathrm{HSA}}=10 \mathrm{mg} / \mathrm{mL}$. Figure 1 shows (a) the absorption and (b) the fluorescence spectra of anthracene in solution at different concentrations of HSA. The growth of the absorption optical density and the fluorescence of anthracene observed with the increasing of HSA concentrations indicates a significant increase of the anthracene content in proteins with the increase of protein microphase. To determine the extinction coefficient of the singlet-singlet absorption of anthracene in HAS, we choose HSA concentration $C_{\mathrm{HSA}}=10 \mathrm{mg} / \mathrm{mL}$. According to the obtained linear dependence of the optical density of the singlet-singlet absorption of anthracene on the wavelength of $360 \mathrm{~nm}$ (Figure 1(c)) bound with the protein globules versus the anthracene concentration in the protein microphase, we define the extinction coefficient of the singlet-singlet absorption of anthracene $\left(2355 \pm 132 \mathrm{M}^{-1} \mathrm{~cm}^{-1}\right)$. Concentration of anthracene molecules in the HSA was obtained according to $D=\varepsilon \cdot C \cdot l$, where $D$ is the optical density of the solution, $\varepsilon$ is the absorption coefficient of anthracene, and $l$ is the length of the absorbing layer $(1 \mathrm{~cm})$.

Since the anthracene is not soluble in water, the obtained results indicate that the HSA binds anthracene that is also confirmed by the results of [24].

Our studies show that eosin efficiently binds with HSA. In [25], it is shown that eosin also binds with bovine serum albumin. 


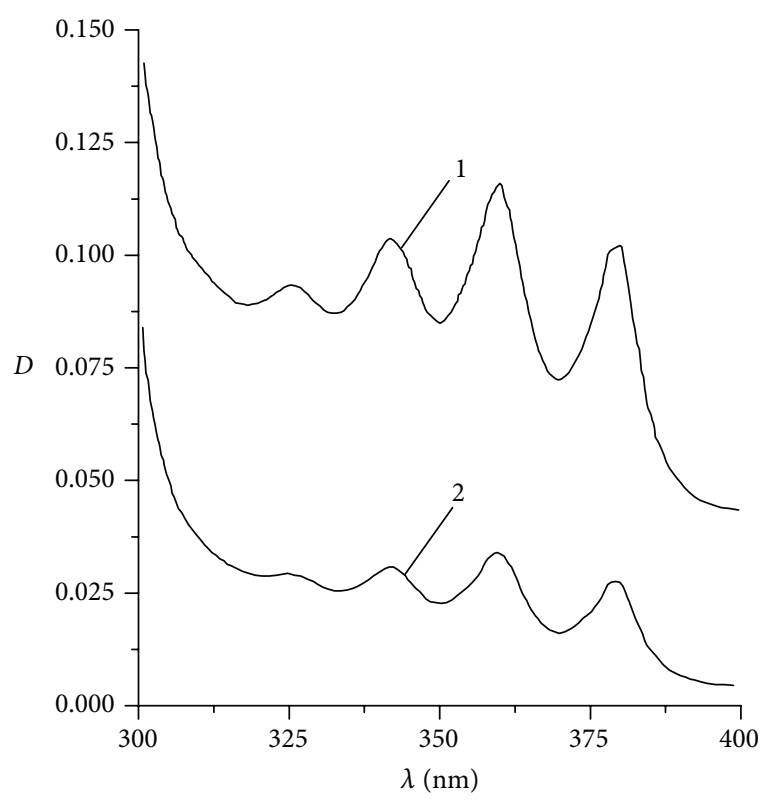

(a)

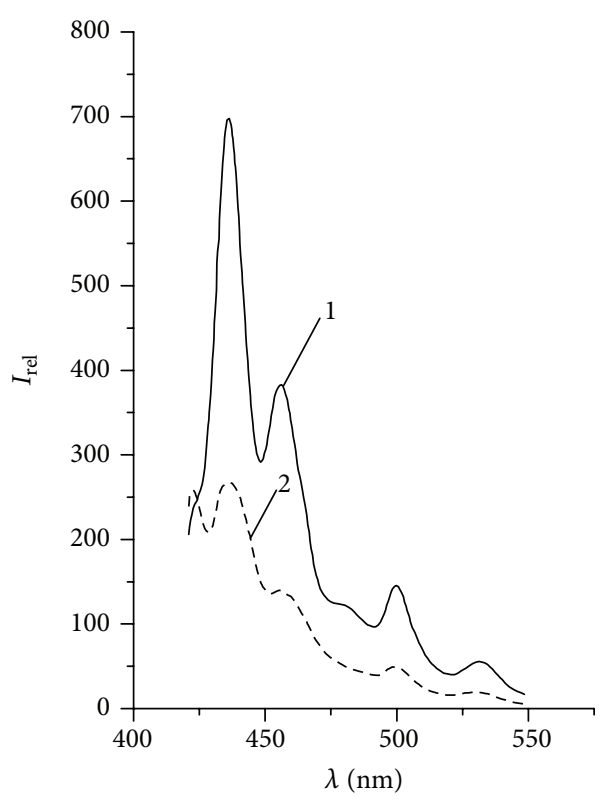

(b)

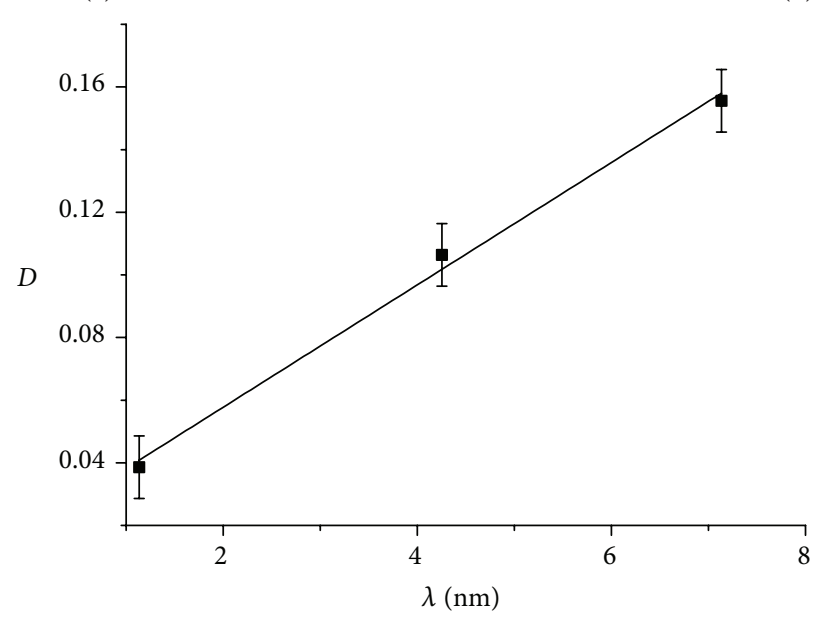

(c)

FIGURE 1: Spectra of (a) absorption and (b) fluorescence of anthracene in HSA (pH 7.4). Curves 1 and 2 correspond to HSA concentrations $C_{\mathrm{HSA}}=10 \mathrm{mg} / \mathrm{mL}$ and $C_{\mathrm{HSA}}=1 \mathrm{mg} / \mathrm{mL}$, respectively. Wavelength of fluorescence excitation is $380 \mathrm{~nm}$. (c) The dependence of optical density of singlet-singlet absorption of anthracene $(\lambda=360 \mathrm{~nm})$ on anthracene concentration in HSA solution $\left(C_{\mathrm{HSA}}=10 \mathrm{mg} / \mathrm{mL}\right)$.

Figure 2 represents spectra of delayed fluorescence (DF) (the maximum at $\lambda_{\max }=550 \mathrm{~nm}$ ) and room temperature phosphorescence (RTP) (the maximum at $\lambda_{\max }=680 \mathrm{~nm}$ ) of eosin in the HSA at different concentrations of HSA.

On the basis of spectral and kinetic studies [13], we found that almost all eosin is gathered at protein globules when HSA concentration in a water solution reaches $C_{\mathrm{HSA}}=1 \mathrm{mg} / \mathrm{mL}$. By changing the eosin concentration, it was obtained that the optimal concentration of eosin in HSA for the registration of prolonged luminescence is $4 \cdot 10^{-6} \mathrm{M}$.

When anthracene is added to a solution of eosin in HAS, an increase of the rate constant of the eosin phosphorescence decay is observed. This is due to the triplet-triplet energy transfer from eosin to anthracene.

When the anthracene concentration lies within 0.8 . $10^{-5} \mathrm{M}$, and $7.8 \cdot 10^{-5} \mathrm{M}$ and the HSA concentration is
$10 \mathrm{mg} / \mathrm{mL}$, the dependence of the rate constant of the phosphorescence decay of eosin $(k)$ on the concentration of anthracene is found to be almost linear (Figure 3, curve 2). For HSA concentration $C_{\mathrm{HSA}}=1 \mathrm{mg} / \mathrm{mL}$, a slight deviation from the linear dependence is observed (curve 1). The resulting relationships can be approximated by straight lines in the $C_{A}$ values interval from $0.5 \cdot 10^{-5} \mathrm{M}$ to $3 \cdot 10^{-5} \mathrm{M}$. These dependencies allow us to determine the effective rate constant of T-T energy transfer $\left(k_{\mathrm{T}-\mathrm{T}}^{\mathrm{ef}}\right)$ in human serum albumin according to the Stern-Volmer equation:

$$
k_{\text {phos }}=\left(k_{\text {phos }}\right)_{0}+k_{\mathrm{T}-\mathrm{T}}^{\mathrm{ef}} \cdot\left[C_{A}\right] \text {, }
$$

where $k_{\text {phos }}$ and $\left(k_{\text {phos }}\right)_{0}$ are rate constants of eosin phosphorescence decay in presence of acceptor anthracene and 


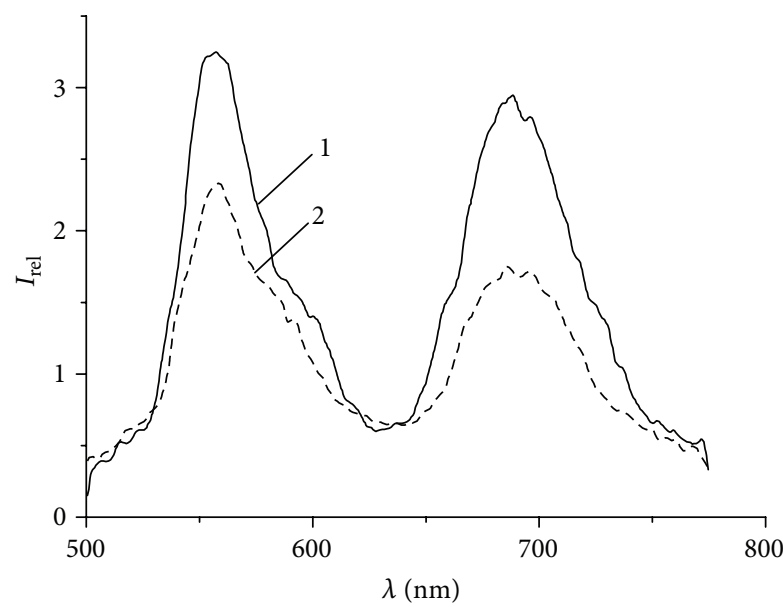

FIgURE 2: Luminescence spectra of eosin $\left(C_{\text {eosin }}=4 \cdot 10^{-6} \mathrm{M}\right)$ in HSA. Curve 1: $C_{\mathrm{HSA}}=10 \mathrm{mg} / \mathrm{mL}$; curve $2: C_{\mathrm{HSA}}=1 \mathrm{mg} / \mathrm{mL}$.

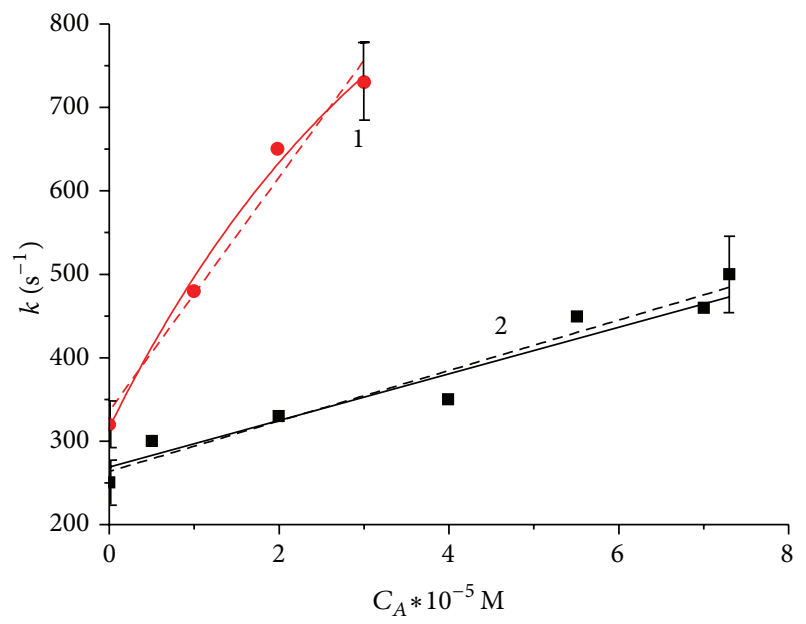

FIgURE 3: Dependences of the rate constant of eosin phosphorescence decay at eosin concentration $4 \cdot 10^{-6} \mathrm{M}$ versus the anthracene concentration $C_{A}$, both bound to serum albumin. HSA concentration is $C_{\mathrm{HSA}}=1 \mathrm{mg} / \mathrm{mL}$ (curve 1 ) and $C_{\mathrm{HSA}}=10 \mathrm{mg} / \mathrm{mL}$ (curve 2). The points represent experimental data, the dashed lines are their least squares approximations, and the solid lines are obtained by calculations.

in its absence, respectively, and $\left[C_{A}\right]$ is the anthracene concentration in HSA. For HSA concentration $C_{\mathrm{HSA}}=1 \mathrm{mg} / \mathrm{mL}$ (Figure 3, curve 1), the effective rate constant of T-T transfer is $14 \cdot 10^{6} \mathrm{M}^{-1} \cdot \mathrm{s}^{-1}$ when the acceptor concentration ranges from $0.8 \cdot 10^{-5} \mathrm{M}$ to $2 \cdot 10^{-5} \mathrm{M}$. When the HSA concentration is $C_{\mathrm{HSA}}=10 \mathrm{mg} / \mathrm{mL}$ (Figure 3, curve 2), the rate constant is $3.0 \cdot 10^{6} \mathrm{M}^{-1} \cdot \mathrm{s}^{-1}$ for the acceptor concentrations ranging from $0.8 \cdot 10^{-5} \mathrm{M}$ to $7.8 \cdot 10^{-5} \mathrm{M}$. With the increasing of the HSA concentration the phosphorescence decay rate constant decreases. It indicates the decarese of the probability of encounter of eosin and anthracene molecules, as a result of the distribution of anthracene molecules over a larger number of HSA globules, and the decrease in the number of anthracene molecules in each protein globule. This is due to the fact that when the HSA concentration is $C_{\mathrm{HSA}}=$ $1 \mathrm{mg} / \mathrm{mL}$, the concentration of protein globules is much smaller than at $C_{\mathrm{HSA}}=10 \mathrm{mg} / \mathrm{mL}$. We hypothesize that as a result eosin and anthracene are more likely localized in the same protein globule at $C=1 \mathrm{mg} / \mathrm{mL}$ than at $C=$ $10 \mathrm{mg} / \mathrm{mL}$. Increased local concentration of donor and acceptor molecules in a single globule may increase the rate constant of T-T energy transfer. Because of this the detection sensitivity of PAHs in proteins is increased.

Thus, these results suggest that the self-assembled system including HSA macromolecule and luminescent probe may be a sensor for PAHs determination.

Since the eosin concentration is significantly lower than the concentration of the protein globules, for definition of TT energy transfers it is necessary to consider the interglobular diffusion of energy donor molecules introduced into a solution of HSA. Let us examine the processes of migration of donor molecules and deactivation of the energy of the donor and acceptor added into a solution of HAS.

(i) Leaving of the donor, that is, eosin molecules in triplet state $\left({ }_{m}^{3} D\right)$, from protein globule $(M)$ to water macrophase:

$$
{ }_{m}^{3} D \stackrel{k_{-1}}{\longrightarrow}{ }^{3} D+M
$$

where ${ }^{3} \mathrm{D}$ is the eosin molecule in triplet state in water phase of solution and $k_{-1}$ is the leaving rate of donor in triplet state from the protein globule.

(ii) penetration of eosin molecule $\left({ }^{3} D\right)$ from aqueous phase to protein globule $(M)$ not containing an anthracene molecule as a result of encounters of eosin molecules with protein globules

$$
{ }^{3} D+M \stackrel{(1-p) k_{1}[M]_{0}}{\longrightarrow}{ }_{m}^{3} D
$$

where $p$ is the probability of the fact that protein globule contains at least one molecule of the energy acceptor, that is, anthracene, $[M]_{0}$ is the protein globules concentration equal to HSA concentration in solution, $k_{1}$ is the rate constant of eosin penetration into protein globule from aqueous macrophase. The value of this rate constant is chosen to be equal to the rate constant of diffusion of eosin molecules in aqueous media $k_{1}=6.5 \cdot 10^{9} \mathrm{M}^{-1} \cdot \mathrm{s}^{-1}$ [26]. We assume that the filling of the globules by anthracene molecules obeys a Poisson distribution similar to filling of surfactant micelles by molecules from polycyclic aromatic hydrocarbons row $[27,28]$

$$
1-p=e^{\bar{p}}
$$

where $\bar{p}$ is the average coefficient of filling of the protein globule by luminescent probes. For our purpose, $\bar{p}=$ $\left[{ }_{m}^{1} A\right] /[M]$, where $\left[{ }_{m}^{1} A\right]$ is the concentration of anthracene in HSA globules. This is equal to the concentration of anthracene added to the HSA solution because all anthracene molecules are bound to protein globules at chosen anthracene concentration. 
(iii) Penetration of the eosin molecules $\left({ }^{3} D\right)$ from an aqueous phase to protein globule $(M)$ containing anthracene molecule:

$$
{ }^{3} D+M \stackrel{p k_{1}[M]_{0}}{\longrightarrow}{ }_{m}^{3} D .
$$

We assume this is accompanied with a high probability by the energy transfer between eosin and anthracene, that is, immediately after the penetration the process ${ }_{m}^{3} D+{ }_{m}^{1} A \stackrel{k_{\mathrm{T}-\mathrm{T}}}{\longrightarrow}$ ${ }_{m}^{1} D+{ }_{m}^{3} A$ takes place. In this case, eosin, located in the globule containing anthracene, goes into the ground singlet state. Therefore, the terms that are responsible for these two processes cancel each other out and do not appear in the equations describing the rate of deactivation energy of the donor molecules ((15), (16)); see below. Analogous assumption is as also used in [27] for water-micellar solutions.

(iv) Deactivation of the electronic excitation energy of donor bound to a protein globule as a result of monomolecular and pseudomonomolecular processes of energy deactivation with the rate constant $k_{2}$ :

$$
{ }_{m}^{3} D \stackrel{k_{2}}{\longrightarrow}{ }_{m}^{1} D+h \nu_{\text {phos }}^{m}
$$

where ${ }_{m}^{1} D$ is the eosin molecule in ground state and $h \nu_{\text {phos }}^{m}$ is the quantum of phosphorescence, emitted by eosin in the triplet state bound to protein globule. The rate constant of monomolecular processes of deactivation of eosin energy $\left(k_{2}\right)$ can be represented by the following equation:

$$
k_{2}=k_{\text {phos }}+k_{q}[Q] \text {, }
$$

where $[Q]$ is the concentration of the quencher (usually, this is a residual molecular oxygen), $k_{\text {phos }}$ is the rate constant of the eosin phosphorescence and $k_{q}$ is the rate constant for quenching of the eosin triplet states by admixtures [Q]. At a constant concentration of quencher $[Q]$ and at the chosen chemical method of solution deoxygenation, the concentration of the residual oxygen reaches $C=1 \mathrm{nM}$ [29], and the summand $k_{q}[Q]$ is the pseudomonomolecular rate constant of the deactivation of triplet states of eosin as a result of encounters with the quencher molecules. According to Figure 3 , the rate constants of donor triplet states deactivation are $340 \mathrm{~s}^{-1}$ and $260 \mathrm{~s}^{-1}$ for HSA concentration $1 \mathrm{mg} / \mathrm{mL}$ and $10 \mathrm{mg} / \mathrm{mL}$, respectively. These values were defined by eosin phosphorescence decay after pulse photoexcitation $\left(k_{2}\right)$ in the absence of acceptor molecules. Reducing of the rate constant of the deactivation in the HSA addition may occur due to an increase of the eosin residence time in globular protein phase. This leads to the reducing of the probability of the encounter of eosin molecules with molecules of the residual oxygen contained in the water.

(v) Monomolecular processes of donor triplet states deactivation in water macrophase $\left(k_{3}\right)$ :

$$
{ }^{3} D \stackrel{k_{3}}{\longrightarrow}{ }^{1} D+h \nu_{\text {phos }}^{w},
$$

where $h \nu_{\text {phos }}^{w}$ is the quantum energy of light irradiated by eosin in water macrophase. In water phase, the rate constant of eosin triplet states deactivation reaches $1300 \mathrm{~s}^{-1}$. (vi) Triplet-triplet transfer of the electronic excitation energy between eosin penetrating from water macrophase to protein globule and anthracene bound to protein globule:

$$
{ }^{3} D+{ }_{m}^{1} A \stackrel{p \cdot k_{1} \cdot[M]_{0}}{\longrightarrow}{ }^{1} D+{ }_{m}^{3} A .
$$

The concentration of proteins containing anthracene $p[M]_{0}$ is chosen approximately equal to the molecular concentration of anthracene $\left[{ }_{m}^{1} A\right]$, since anthracene is practically insoluble in water.

On the base of the adduced processes, the equation of triplet states deactivations of eosin molecules can be written as follows:

(a) for the donor molecules bound to the protein globule:

$$
\frac{d\left[{ }_{m}^{3} D\right]}{d t}=k_{1}[M]\left[{ }^{3} D\right]-k_{-1}\left[{ }_{m}^{3} D\right]-k_{2}\left[{ }_{m}^{3} D\right],
$$

(b) for the donor molecules in the water macrophase:

$$
\begin{aligned}
& \frac{d\left[{ }^{3} D\right]}{d t} \\
& =-k_{1}[M]\left[{ }^{3} D\right]-k_{1}\left[{ }_{m}^{1} A\right]\left[{ }^{3} D\right]+k_{-1}\left[{ }_{m}^{3} D\right]-k_{3}\left[{ }^{3} D\right] .
\end{aligned}
$$

Here, $[M]=(1-p)[M]_{0}$ is the concentration of the anthracene-free protein globules. The first term of (15) describes the entry of the excited eosin molecules into the anthracene-free globules. The second term takes into account the exit of eosin in the excited state from the protein globules, and the third one corresponds to the monomolecular processes of deactivation of the excited eosin. The first term of (16) takes into account the transition of the excited eosin from the water macrophase to the protein globules without anthracene. The second term is responsible for the entrance of the excited eosin to the protein globule with anthracene. In fact, the second term describes the eosin deactivation by the $\mathrm{T}$-T transfer at the entrance of the excited eosin to the protein globule with anthracene. The third term takes into account the monomolecular processes of the eosin deactivation in water macrophase.

The solution of linear differential equations (15) and (16) is a sum of two exponentials whose exponents are the roots of the characteristic equation of the system. Both of them are negative and have magnitudes $10^{5}$ and $10^{2}$, respectively. Hence, the first exponential term decays much faster than the second one, and, neglecting it, one can write the solution as $\left[{ }^{3} D\right],\left[{ }_{m}^{3} D\right] \sim \exp (-k t)$. Here, $k$ is the smallest by magnitude characteristic number which plays the role of the decay rate of the eosin phosphorescence.

We are interested in the dependence of $k$ on the concentration of anthracene $C_{A}$ and on the concentration of HSA. Graphs of this relationship are shown in Figure 3 by solid lines. The best agreement between experimental and theoretical data is achieved with the following parameters: $k_{1}=6.5 \cdot 10^{9} \mathrm{M}^{-1} \cdot \mathrm{s}^{-1}, k_{3}=1300 \mathrm{~s}^{-1}$; for HSA concentration 
of $C_{\mathrm{HSA}}=10 \mathrm{mg} / \mathrm{mL}: k_{-1}=750 \mathrm{~s}^{-1}, k_{2}=260 \mathrm{~s}^{-1}$; for the concentration of HAS $C_{\mathrm{HSA}}=1 \mathrm{mg} / \mathrm{mL}: k_{-1}=500 \mathrm{~s}^{-1}$, $k_{2}=320 \mathrm{~s}^{-1}$.

The values were quite large, which justifies the accounting of the process of the exit of eosin molecules from a protein globule when considering the processes of deactivation of the eosin triplet states in protein microphase. Under these experimental conditions, we did not observe an absorption and fluorescence spectra of eosin in the water macrophase. This can be explained by the fact that the rate constant for eosin leaving from the protein globule is less than the rate constant of the eosin entry into the protein globule. Consequently, eosin is predominantly localized in the protein microphase. Its concentration in the aqueous macrophase is much less than in protein microphase. This makes it difficult to record absorption and fluorescence spectra of eosin in water macrophase.

\section{Conclusion}

Thus, T-T transfer between luminescent probe and PAH, both bound to protein, occurring when the probe concentration is much lower than the concentration of protein globules may be sustained by interglobular diffusion of hydrophilic polar donor (eosin).

It is shown that the self-assemble system consisting of a HSA macromolecule and a fluorescent probe may be a sensor for PAHs determination. To achieve the optimal sensitivity, the appropriate ratios between components of the sensor, namely, HSA, eosin, and anthracene, were suggested.

Self-assembled luminescent sensor based on HSA macromolecule and probes noncovalently bound to the protein allows the detection of the carcinogenic PAH molecules in proteins by means of the registration of the change in the kinetics of the eosin probe phosphorescence decay. Sensitivity of determination of PAHs by the suggested sensor increases in the decreasing of the content of proteins in the solution to $C_{\mathrm{HSA}}=1 \mathrm{mg} / \mathrm{mL}$.

\section{Acknowledgments}

This study was supported in part by RF Governmental Contracts 14.B37.11.0563 and by Russian Foundation for Basic Research, Grant N12-02-31196.

\section{References}

[1] H. V. Hsieh, D. B. Sherman, S. A. Andaluz, T. J. Amiss, and J. B. Pitner, "Fluorescence resonance energy transfer glucose sensor from site-specific dual labeling of glucose/galactose binding protein using ligand protection," Journal of Diabetes Science and Technology, vol. 6, no. 6, pp. 1286-1295, 2012.

[2] I. L. Medintz, E. R. Goldman, M. E. Lassman, and J. M. Mauro, "A fluorescence resonance energy transfer sensor based on maltose binding protein," Bioconjugate Chemistry, vol. 14, no. 5, pp. 909-918, 2003.

[3] H. M. Green and J. Alberola-Ila, "Development of ERK activity sensor, an in vitro, FRET-based sensor of extracellular regulated kinase activity," BMC Chemical Biology, vol. 5, 2005.
[4] J. R. Escabi-Perez, F. Nome, and J. H. Fendler, "Energy transfer in micellar systems. Steady state and time resolved luminescence of aqueous micelle solubilized naphthalene and terbium chloride," Journal of the American Chemical Society, vol. 99, no. 24, pp. 7749-7754, 1977.

[5] J. R. Darwent, W. Dong, C. D. Flint, and N. W. Sharpe, "Intermolecular energy transfer between phenanthrene and lanthanide ions in aqueous micellar solution," Journal of the Chemical Society, Faraday Transactions, vol. 89, no. 6, pp. 873880, 1993.

[6] J. P. Chauvet, M. Bazin, and R. Santus, "On the triplet-triplet energy transfer from chlorophyll to carotene in triton $\mathrm{x} 100$ micelles," Photochemistry and Photobiology, vol. 41, pp. 83-90, 1985.

[7] K. M. Sanchez, D. E. Schlamadinger, J. E. Gable, and J. E. Kim, "Förster resonance energy transfer and conformational stability of proteins: an advanced biophysical module for physical chemistry students," Journal of Chemical Education, vol. 85, no. 9, pp. 1253-1256, 2008.

[8] H. Zemel and B. M. Hoffman, "Long-range triplet-triplet energy transfer within metal-substituted hemoglobins," Journal of the American Chemical Society, vol. 103, no. 5, pp. 1192-1201, 1981.

[9] J. Tian, X. Liu, Y. Zhao, and S. Zhao, "Studies on the interaction between tetraphenylporphyrin compounds and bovine serum albumin," Luminescence, vol. 22, no. 5, pp. 446-454, 2007.

[10] A. Husain, J. Ovadia, and L. I. Grossweiner, "Pulse radiolysis of the eosin-human serum albumin complex," Transactions of the Faraday Society, vol. 66, pp. 1472-1484, 1970.

[11] V. L. Ermolaev, E. G. Sveshnikova, and T. A. Shakhverdov, "Energy transfer between organic molecules and transition metal ions," Russian Chemical Reviews, vol. 44, no. 1, pp. 26-40, 1975.

[12] A. G. Mel'Nikov, A. M. Saletskii, V. I. Kochubey, A. B. Pravdin, I. S. Kurchatov, and G. V. Mel'Nikov, "Triplet-triplet energy transfer between luminescent probes bound to albumins," Optics and Spectroscopy, vol. 109, no. 2, pp. 188-192, 2010.

[13] A. M. Saletskii, A. G. Mel'nikov, A. B. Pravdin, V. I. Kochubei, and G. V. Mel'nikov, "Structural changes in human serum albumin according to the data on the phosphorescence kinetics of a luminescent probe-eosin," Journal of Applied Spectroscopy, vol. 72, no. 5, pp. 723-727, 2005.

[14] E. V. Naumova, A. G. Melnikov, and G. V. Melnikov, "Luminescence quenching by heavy metal ions of probes based on anthracene, pyrene, and eosin in human serum albumin," Journal of Applied Spectroscopy, vol. 80, no. 2, pp. 159-163, 2013.

[15] K. Kikuchi, H. Kokubun, and M. Koizumi, "Studies of triplet energy transfer by means of an emission-absorption flash technique. i. reversible energy transfer between xanthene dyes and anthracenes," Bulletin of the Chemical Society of Japan, vol. 43, pp. 2732-2739, 1970.

[16] G. A. Ketsle, L. V. Levshin, G. V. Melnikov, and B. F. Minaev, "Mechanism of the effect of a magnetic field on mixed-type triplet-triplet annihilation," Optics and Spectroscopy, vol. 51, no. 4, pp. 367-369, 1981.

[17] P. B. Farmer, O. Sepai, R. Lawrence et al., "Biomonitoring human exposure to environmental carcinogenic chemicals," Mutagenesis, vol. 11, no. 4, pp. 363-381, 1996.

[18] M. McKenzie, T. McLemore, and P. Rankin, "A human plasma component that binds benzo(a)pyrene," Cancer, vol. 42, no. 6 , pp. 2733-2737, 1978.

[19] S. L. Tannheimer, S. L. Barton, S. P. Ethier, and S. W. Burchiel, "Carcinogenic polycyclic aromatic hydrocarbons increase 
intracellular $\mathrm{Ca}^{2+}$ and cell proliferation in primary human mammary epithelial cells," Carcinogenesis, vol. 18, no. 6, pp. 1177-1182, 1997.

[20] D. Yu, M. G. Kazanietz, R. G. Harvey, and T. M. Penning, "Polycyclic aromatic hydrocarbon o-Quinones inhibit the activity of the catalytic fragment of protein kinase C," Biochemistry, vol. 41, no. 39, pp. 11888-11894, 2002.

[21] K. Skupińska, M. Zylm, I. Misiewicz, and T. Kasprzycka-Guttman, "Interaction of anthracene and its oxidative derivatives with human serum albumin," Acta Biochimica Polonica, vol. 53, no. 1, pp. 101-112, 2006.

[22] V. M. Mazhul and D. G. Scherbin, "Tryptophan phosphorescence as a monitor of flexibility of membrane proteins in cells," in Advances in Fluorescence Sensing Technology III, Proceedings of SPIE, pp. 507-514, February 1997.

[23] C. A. Parker, Photoluminescence of Solutions: with Applications to Photochemistry and Analytical Chemistry, Elsevier, 1968.

[24] A. M. Saletskii, A. G. Mel'Nikov, A. B. Pravdin, V. I. Kochubei, and G. V. Meln'ikov, "Complexation of pyrene and anthracene with human blood plasma," Journal of Applied Spectroscopy, vol. 75, no. 3, pp. 402-406, 2008.

[25] A. A. Waheed, K. S. Rao, and P. D. Gupta, "Mechanism of dye binding in the protein assay using eosin dyes," Analytical Biochemistry, vol. 287, no. 1, pp. 73-79, 2000.

[26] V. L. Ermolaev, E. N. Bodunov, E. B. Sveshnikova, and T. A. Shakhverdov, Nonradiative Transfer of Electronic Excitation Energy, Nauka, Leningrad, Russia, 1977, (Russian).

[27] K. Gläsle, U. K. A. Klein, and M. Hauser, "Intermicellar exchange dynamics of solubilized reactants," Journal of Molecular Structure, vol. 84, no. 3-4, pp. 353-360, 1982.

[28] G. Rothenberger, P. P. Infelta, and M. Grätzel, "Dynamics and statistics of triplet-triplet annihilation in micellar assemblies," Journal of Physical Chemistry, vol. 85, no. 13, pp. 1850-1856, 1981.

[29] S. Z. Kananovich and V. M. Mazhul', "Fluorimetric analysis of the structural-dynamic state of alkaline phosphatase of Escherichia coli," Journal of Applied Spectroscopy, vol. 70, no. 5, pp. 765-769, 2003. 

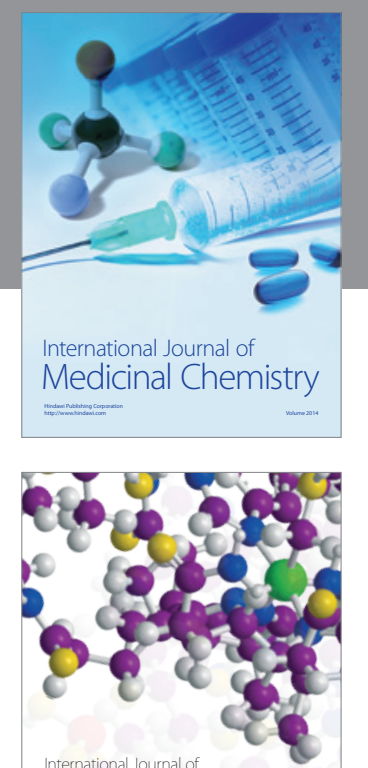

\section{Carbohydrate} Chemistry

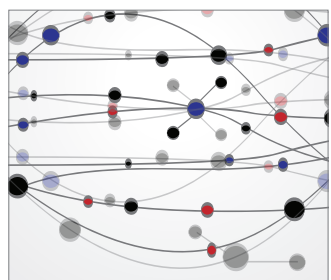

The Scientific World Journal
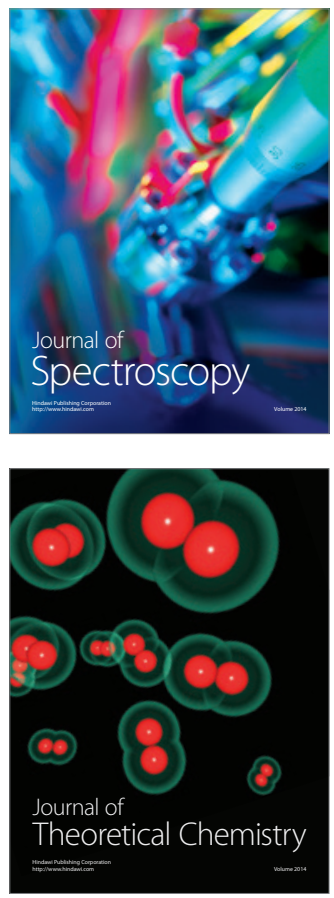
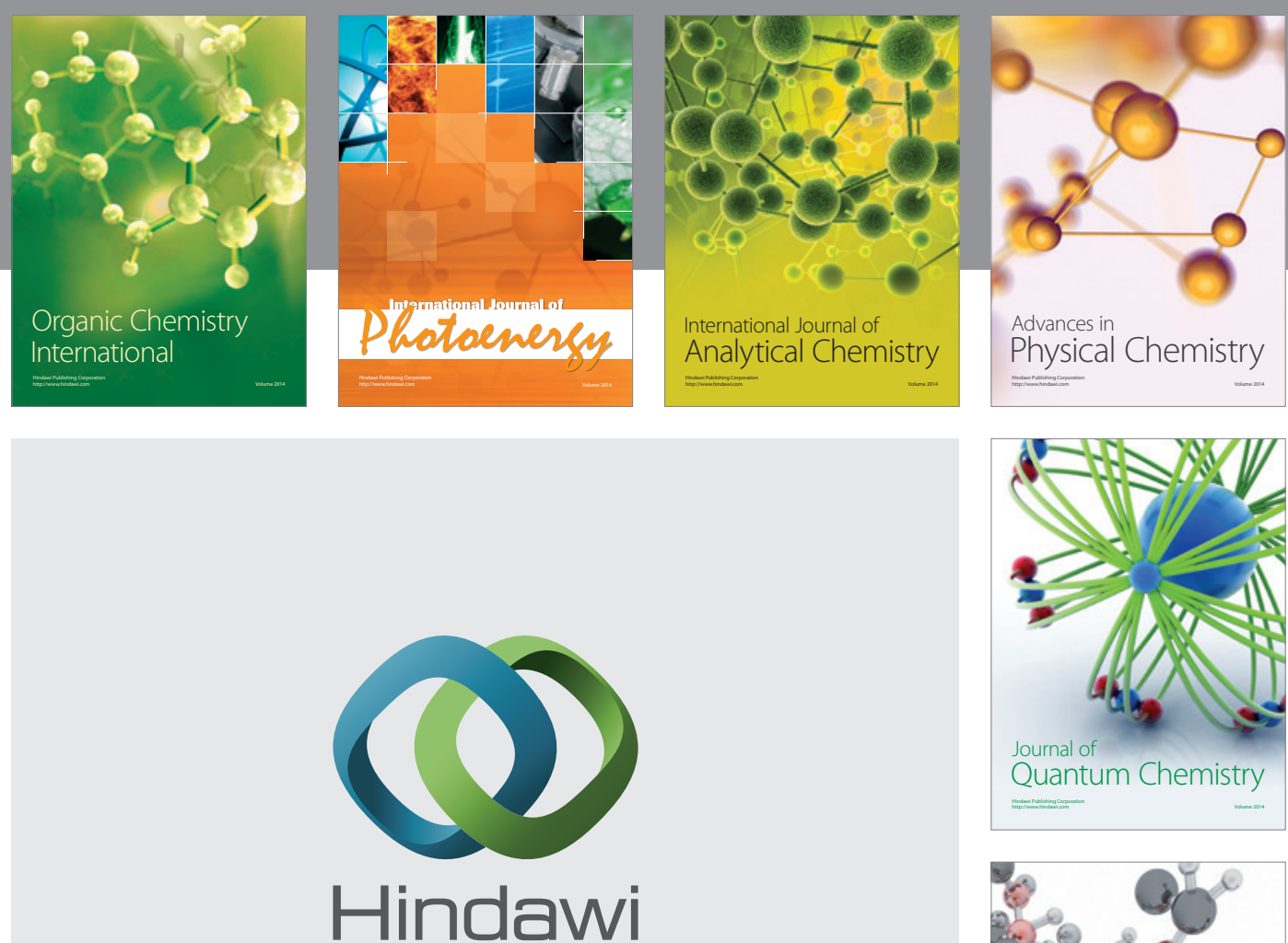

Submit your manuscripts at

http://www.hindawi.com

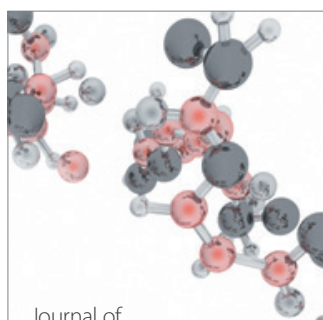

Analytical Methods

in Chemistry

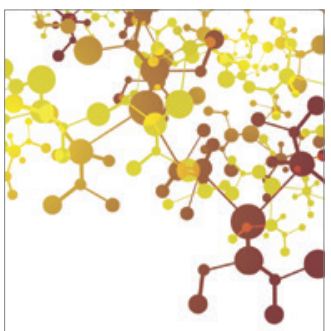

Journal of

Applied Chemistry

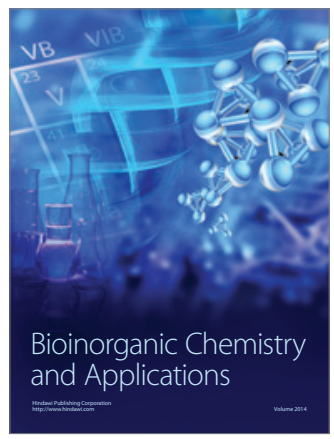

Inorganic Chemistry
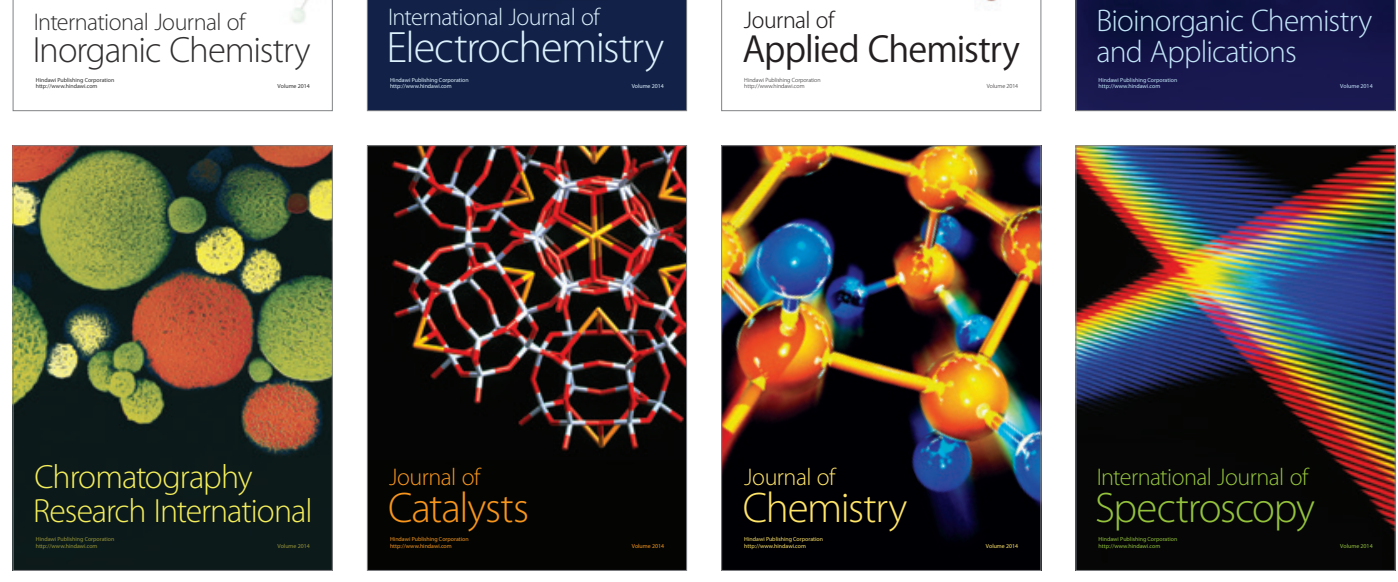